6. Popp AI, Armstrong D, Sepkowitz KA. Recurrent panniculitis in a patient receiving protease inhibitor therapy for human immunodeficiency virus infection. Clin Infect Dis 1999; 29:936-937.

7. Venkataramani A, Behling CA, Lyche KD. Sclerosing mesenteritis: an unusual cause of abdominal pain in an HIV-positive patient. Am / Gastroenterol 1997; 92:1059-1060.
8. Maillard H, Prophette B, Coss F, Celerier P, Forest JL, Varache N, et al. Panniculits in an immunosuppressed patient. Ann Pathol 1996; 16:139-140.

9. Carlson KC, Mehlmauer M, Evans S, Chandrasoma P. Cryptococcal cellulitis in renal transplant recipients. / Am Acad Dermatol 1987; 17:469-472.

\title{
HIV prevention and treatment research in sub-Saharan Africa: where are the adolescents?
}

Some two decades into the, predominantly heterosexual, HIV epidemic in sub-Saharan Africa, we have yet to challenge the epidemic in a concerted fashion in perhaps its most pertinent population. Not only has little intervention research been carried out on adolescents in sub-Saharan Africa but also the trials that have involved this group do not seem to have been given due attention.

The continued spread of new HIV infections and rapidly increasing morbidity and mortality characterize the maturing HIV epidemic in sub-Saharan Africa. The latest AIDS epidemic update was released in December 2005 by UNAIDS [1]. It reminds us yet again that subSaharan Africa bears an increasingly disproportionate burden of global HIV infection. Despite being home to only one-tenth of the global population, over $60 \%$ of all adults and children living with HIV and AIDS live in sub-Saharan Africa; $65 \%$ of those newly acquiring HIV (4.9 million) in 2005 were from this region, and approximately $75 \%$ of global deaths from HIV/AIDS (3.1 million) occurred here [1].

In $2004,50 \%$ of new infections occurred in young adults [2]. In contrast to the demographic profile of more industrialized regions, in sub-Saharan Africa people under the age of 24 years constitute the majority of the population. More than two-fifths of the entire population is under 15 years of age in this region [3]. It is here that we need to aim our efforts.

Pettifor et al. [4,5] recently highlighted the central role that young women aged 15-24 years play in fuelling the HIV epidemic in South Africa (one of the worst affected countries in the world). This profile of young women bearing the brunt of the pandemic is not unique to South Africa but a common feature of HIV infection in subSaharan Africa. The infection rates in young women of this age group are up to six times higher than in their male counterparts in parts of sub-Saharan Africa [6]. Biological, behavioral, and socioeconomic characteristics increase the HIV risk in youth and especially in young women. Less than half of all young people are able to identify correctly the major ways of preventing HIV infection, some 20 years into the heterosexual epidemic in this region [1].

While the rising incidence and prevalence of HIV create a scientific and ethical imperative to undertake prevention and treatment research in these settings, a recent
Cochrane analysis of HIV-related trials underway or completed in sub-Saharan Africa by December 2004 highlights the dispiriting state of HIV-related prevention or HIV-related treatment trials in sub-Saharan Africa [7]. The analysis examined trials that focused on prevention or treatment of HIV or any associated factor, for example opportunistic infections.

Siegfried et al. [7] scanned 12815 records resulting in 284 eligible records, of which 150 referring to 77 trials were included in their analysis. Of 67 trails whose publications were accessible to us, we found that only 19 of the 67 trials may possibly have included adolescents, given their enrolment criteria; none of these trials focused specifically on young people by identifying or undertaking subgroup analysis in this age group. Of the 30 trials involving women's issues (including pMTCT), five may possibly have included adolescents.

While there is growing support for evidence-based decision making and the randomized controlled trial as the gold standard for evaluating new interventions, proofs of prevention methods should be made through goodquality research in the population that is most affected. New treatment modalities should likewise be evaluated in the settings where their need is greatest. In the case of HIV infection, globally and in sub-Saharan Africa, the epidemiological data provide a compelling basis for prioritization of interventions targeted at adolescents and indicate the need to include adolescents in HIV treatment and especially prevention trials. This has yet to happen.

Our research efforts must be informed and responsive to where the needs are greatest demographically. We must focus urgently on prevention and treatment interventions in young people in Africa, as well as developing a more strategic and structured approach to reducing HIV risk in adolescents, if we are to impact the current epidemic trajectories.

\section{Acknowledgements}

The authors would like to thank Nandi Siegfried for furnishing details of the trials referred to and Cheryl Baxter for assistance in record retrieval and in submission.

Vivek Naranbhai a and Quarraisha Abdool Karim ${ }^{a, b}$, ${ }^{a}$ CAPRISA Women and AIDS Programme, Doris Duke 
Medical Research Institute, Nelson R Mandela School of Medicine, University of KwaZulu-Natal, Congella, South Africa; ${ }^{b}$ Department of Epidemiology, Mailman School of Public Health, Columbia University, New York, USA.

Received: 6 December 2005; accepted: 26 January 2006.

\section{References}

1. UNAIDS. AIDS Epidemic Update: December 2005.Geneva: UNAIDS; 2005.
2. UNAIDS. Fourth Report on the Global AIDS epidemic (UNAIDS/ 04.16E). Geneva: UNAIDS; 2004.

3. Population Reference Bureau. World Population Data Sheet, 2005. Washington, DC: Population Reference Bureau; 2005.

4. Pettifor AE, Rees HV, Kleinschmidt I, Steffenson AE, MacPhail C, Hlongwa-Madikizela $L$, et al. Young people's health in South Africa: HIV prevalence and sexual behaviours from a nationally representative household survey. AIDS 2005; 19:1525-1534.

5. Pettifor AE, Kleinschmidt I, Levin J, Rees HV, MacPhail C, Madikizela-Hlongwa $\mathrm{L}$, et al. A community-based study to examine the effect of a youth HIV prevention intervention on young people aged 15-24 in South Africa: results of the baseline survey. Trop Med Int Health 2005; 10:971.

6. Kaiser Family Foundation. Fact Sheet: The Global Impact of HIV/ AIDS on Youth. New York Kaiser Family Foundation; 2004.

7. Siegfried N, Clarke M, Volmink J. Randomised controlled trials in Africa of HIV and AIDS: descriptive study and spatial distribution. Br Med / 2005; 331:742. 